\title{
Maternal excessive gestational weight gain as a risk factor for autism spectrum disorder in offspring: a systematic review
}

\author{
Sorayya Kheirouri ${ }^{*^{*}}$ (D) and Mohammad Alizadeh ${ }^{2^{*}}$
}

\begin{abstract}
Background: Abnormal gestational weight gain (GWG) is a prenatal complication that may contribute to long-term behavioral and neurodevelopmental differences in offspring. This systematic review summarizes research on the association between maternal GWG and risk of autism spectrum disorder (ASD) in offspring.

Methods: Google and electronic databases, including PubMed, SCOPUS, Embase, Cochrane Library and Google Scholar, were searched for original human studies published in English through June 2020. Articles that examined the association between GWG and risk of ASD in offspring were included. Duplicate and irrelevant studies were removed; and data were obtained through critical analysis.

Results: Of 96 articles searched, eight studies were included in the final review. All studies $(n=7)$ investigating the association of maternal excessive GWG with risk of ASD in offspring indicated that high GWG was independently associated with an increased risk of ASD. Of five studies investigating the association of inadequate GWG with the risk of ASD, four indicated that low GWG was not associated with an increased risk of ASD. Of seven studies examining the association of maternal pre-pregnancy BMI or weight with the risk of ASD, five reported that maternal pre-pregnancy BMI or weight did not appear to be independently associated with risk of ASD. The GWGASD association is independent of maternal BMI and child's intellectual disability, but offspring's genetic susceptibility connection to the GWG-ASD association remains a topic of debate.

Conclusions: The findings suggest that maternal excessive GWG may be associated with increased risk of ASD in offspring. However, insufficient GWG does not appear to have such association.
\end{abstract}

Keywords: Autism spectrum disorder, Body mass index, Gestational weight gain, Intellectual disability, Genetic susceptibility

\section{Background}

Autism spectrum disorder (ASD) is a neurobehavioral disturbance that affects social, communication and behavioral development and can include significant language challenges. According to a 2020 report based on 2016 data from the Centers for Disease Control and

\footnotetext{
* Correspondence: kheirouris@tbzmed.ac.ir; mdalizadeh@tbzmed.ac.ir ${ }^{1}$ Department of Nutrition, Tabriz University of Medical Sciences, Attar Nishabouri St., POBOX: 14711, Tabriz, IR Postal code: 5166614711, Iran ${ }^{2}$ Nutrition Research Center, Tabriz University of Medical Sciences, Tabriz, Iran
}

Prevention (CDC), ASD prevalence is 1 in 54 children in the United States [1]. The increasing number of people with ASD in recent decades [1] indicates a need for further study of its underlying etiology.

The exact cause of ASD is largely unknown. According to the literature, its etiology is multifactorial and many risk factors, including genetics $[2,3]$, prenatal and perinatal factors $[4,5]$, neuroanatomical abnormalities [6,7], and environmental factors [8] may be involved in the development of ASD.

C C The Author(s). 2020 Open Access This article is licensed under a Creative Commons Attribution 4.0 International License, which permits use, sharing, adaptation, distribution and reproduction in any medium or format, as long as you give appropriate credit to the original author(s) and the source, provide a link to the Creative Commons licence, and indicate if changes were made. The images or other third party material in this article are included in the article's Creative Commons licence, unless indicated otherwise in a credit line to the material. If material is not included in the article's Creative Commons licence and your intended use is not permitted by statutory regulation or exceeds the permitted use, you will need to obtain permission directly from the copyright holder. To view a copy of this licence, visit http://creativecommons.org/licenses/by/4.0/ The Creative Commons Public Domain Dedication waiver (http://creativecommons.org/publicdomain/zero/1.0/) applies to the data made available in this article, unless otherwise stated in a credit line to the data. 
The prenatal period is a critical period for atypical brain development in people with ASD [9]. Various prenatal complications, such as maternal gestational diabetes $[10,11]$, advanced parental age [11, 12], bleeding [11], use of prescription medication for the treatment of neuropsychological disorders during pregnancy $[13,14]$, and meconium in the amniotic fluid [15], have been identified as possible risk factors for ASD during the inutero period. Abnormal gestational weight gain (GWG) is another prenatal complication which may contribute to long-term behavioral and neurodevelopmental differences in offspring [16-18].

Gestational weight gain is the amount of weight gained by mothers during the period between conception and delivery. Using the mother's pre-pregnancy body mass index (BMI), acceptable weight gain was classified by the Institute of Medicine (IOM) in 2009. The amount of weight gained during pregnancy influences both maternal and pediatric outcomes and is important to the immediate and the long-term health of both mother and infant. Previous investigations indicated the detrimental influence of undesirable GWG on cognitive development $[18,19]$. Excessive GWG has been associated with increased risk of macrosomia [20], neurodevelopmental outcomes and behavioral disorders [21], and prepubertal and postpubertal obesity [22].

Numerous studies have evaluated the association between unfavorable GWG and risk of ASD in children [23-30]. The present systematic review evaluated and summarized current literature in order to determine if a relationship exists between maternal GWG and risk of ASD in offspring.

\section{Methods}

\section{Search strategy and selection criteria}

PRISMA protocol guidelines (2015) were used for this systematic review. A literature search was conducted in the electronic databases of PubMed, SCOPUS, Embase, Cochrane Library and Google Scholar, in addition to Google itself, for all dates up to June 2020 (Table 1). Original articles published in English addressing the relationship between maternal GWG and risk of ASD in

Table 1 Association between gestational weight gain and risk of autism spectrum disorders: Method of the database search strategy using PubMed, SCOPUS, Google Scholar and Embase

\begin{tabular}{|c|c|c|}
\hline $\begin{array}{l}\text { Database (Search conducted } \\
\text { up to June } 27,2020)\end{array}$ & Search terms ${ }^{a}$ & $\begin{array}{l}\text { Number of } \\
\text { studies searched }\end{array}$ \\
\hline \multirow[t]{3}{*}{ PubMed } & $\begin{array}{l}\text { \#1 (((gestational weight gain [Title/Abstract]) OR (pregnancy weight gain [Title/Abstract])) OR } \\
\text { (weight gain in pregnancy[Title/Abstract])) OR (weight gain during pregnancy[Title/Abstract]) }\end{array}$ & 4323 \\
\hline & $\begin{array}{l}\text { \#2 (((autism[Title/Abstract]) OR (ASD[Title/Abstract])) OR (developmental delay[Title/Abstract])) } \\
\text { OR (developmental disorder[Title/Abstract]) }\end{array}$ & 64,806 \\
\hline & $\begin{array}{l}\text { \#1 combined with \#2 ((((gestational weight gain[Title/Abstract]) OR (pregnancy weight } \\
\text { gain[Title/Abstract])) OR (weight gain in pregnancy[Title/Abstract])) OR (weight gain during } \\
\text { pregnancy[Title/Abstract])) AND ((((autism[Title/Abstract]) OR (ASD[Title/Abstract])) OR } \\
\text { (developmental delay[Title/Abstract])) OR (developmental disorder[Title/Abstract])) }\end{array}$ & 15 \\
\hline SCOPUS & $\begin{array}{l}\text { (TITLE-ABS-KEY ("gestational weight gain") OR TITLE-ABS-KEY ("pregnancy weight gain") OR } \\
\text { TITLE-ABS-KEY ("weight gain in pregnancy") OR TITLE-ABS-KEY ("weight gain during preg- } \\
\text { nancy") AND TITLE-ABS-KEY ("autism") OR TITLE-ABS-KEY ("ASD”) OR TITLE-ABS-KEY ("develop- } \\
\text { mental delay") OR TITLE-ABS-KEY (“developmental disorder")) AND DOCTYPE (ar) }\end{array}$ & 24 \\
\hline \multirow[t]{3}{*}{ Google Scholar } & $\begin{array}{l}\text { allintitle: "autism" OR "ASD" OR "developmental delay" OR "developmental disorder" "weight } \\
\text { gain" }\end{array}$ & 24 \\
\hline & $\begin{array}{l}\text { with at least one of the words: "autism" OR "ASD" OR "developmental delay" OR } \\
\text { "developmental disorder" }\end{array}$ & \\
\hline & with the exact phrase: weight gain & \\
\hline \multirow[t]{3}{*}{ Embase } & $\begin{array}{l}\text { \#1 'gestational weight gain'/exp. OR 'pregnancy weight gain'/exp. OR 'weight gain in } \\
\text { pregnancy' OR 'weight gain during pregnancy' }\end{array}$ & 4356 \\
\hline & $\begin{array}{l}\text { \#2 'autism'/exp. OR 'asd'/exp. OR 'developmental delay'/exp. OR 'developmental disorder'/ } \\
\text { exp. }\end{array}$ & 139,670 \\
\hline & \#1 AND \#2 & 28 \\
\hline \multirow[t]{3}{*}{ Cochrane library } & $\begin{array}{l}\text { \#1 ("gestational weight gain"):ti,ab,kw OR ("pregnancy weight gain"):ti,ab,kw OR (“weight gain } \\
\text { in pregnancy"):ti,ab,kw OR ("weight gain during pregnancy"):ti,ab,kw }\end{array}$ & 791 \\
\hline & $\begin{array}{l}\text { \#2 ("autism"):ti,ab,kw OR (“autism spectrum disorder"):ti,ab,kw OR (“ASD”):ti,ab,kw OR } \\
\text { ("developmental delay"):ti,ab,kw OR ("developmental disorder"):ti,ab,kw }\end{array}$ & 4481 \\
\hline & \#1 AND \#2 & 1 \\
\hline Total & & 92 \\
\hline
\end{tabular}

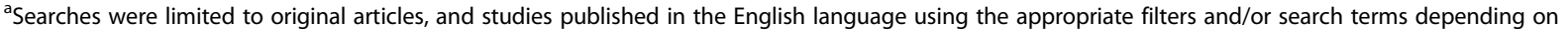
the database 
offspring were included. Studies on intellectual disability without concurrent ASD diagnosis, neurologic (epilepsy), or other psychiatric diseases (depression, psychosis and anxiety) were excluded. As shown in Table 1, keywords employed for the search were as follows: "gestational weight gain" OR "pregnancy weight gain" OR "weight gain in pregnancy" OR "weight gain during pregnancy" in title-abstract-keywords AND "autism" OR "ASD" OR "developmental delay" OR "developmental disorder" in title-abstract-keywords. The research question was: What is the relationship between maternal GWG and risk of ASD in the child?

\section{Study screening}

Studies retrieved from the search were transferred to an Endnote file and duplicate articles were removed. Titles and abstracts of the remaining articles were assessed by two independent reviewers to screen articles within the scope of this review. Full texts of screened studies were then critically reviewed for eligibility and data extraction. Reference lists of the articles was manually searched to identify additional studies; and when full text of an article was not accessible, it was requested from authors by email. Review articles, animal studies, conference papers, and studies that assessed the relationship of GWG with other health issues such as diabetes or hypertension were excluded. Discrepancies between the two reviewers were resolved through discussion.

\section{Data extraction}

The extracted data included first author and year of publication, country and study design, number of children, age of children, covariates, GWG definition, ASD definition, findings accompanied by odds ratio, confidence intervals or other indicators of correlation, and $p$ value, if available.

\section{Risk of bias and quality assessment}

Selected studies were assessed for methodological quality by two independent reviewers. As shown in supplementary Tables 3 and 4, the Newcastle-Ottawa quality and risk of bias assessment tool for observational cohort and case-control studies [31] was used to evaluate the quality and risk of bias of the included studies based on three domains: selection of exposed and non-exposed groups and ascertainment of exposure; comparability of groups on the basis of the design or analysis controlled for confounders; and outcome regarding assessment and followup time. A star system was applied to classify articles as good, fair, or poor quality. Studies with a total score of 6 or higher were considered high quality.

\section{Results}

\section{Selection of studies}

As shown in Fig. 1, 92 studies were found using the electronic search strategy and four studies were identified through hand searching for a total of 96 that were assessed. Duplicates were deleted, leaving 57 studies. Of those, 13 publications met the topic and scope of the study during screening phase. During the critical review phase, six studies were excluded due to unavailability of full text $(n=1)$, lack of relevance to the study topic $(n=$ 4 ), and a summary of Xiang et al. study [30] $(n=1)$. Hence, a total of seven articles were included in the final review (Fig. 1). The study of Bilder et al. [23] consisted of two different population- and research-based genetic studies, which were considered to be separate studies for the purpose of this review. Therefore, the total count of studies was eight for the final analysis.

\section{Characteristics of the included studies}

Table 2 shows the characteristics of the included studies. All articles were published between 2010 and 2019 and were observational studies (six cohort and three case control). No randomized controlled trial studies were found. All reviewed articles except Dodds et al. study [25] investigated singleton births. Dodds et al. included both singleton and multiple births; however, they adjusted for the effect of multiple births on the relationship between GWG and risk of ASD [25]. All included studies considered the effects of principal confounder factors, including child's gender, age, birth year, genetic susceptibility, intellectual disability, and mother's pre-pregnancy BMI, weight, age, education, race/ethnicity, parity, smoking, family income, history of comorbidity, gestational age, as well as father's age in analyzing the association between maternal GWG and offspring ASD risk. To identify ASD, four of the included studies used ICD (International Statistical Classification of Diseases and Related Health Problems), three studies used DSM-IV-TR (Diagnostic and Statistical Manual of Mental Disorders, fourth edition, text revision), two studies used ADOS-G (Autism Diagnostic Observation Schedule Generic) and two studies used ADI-R (Autism Diagnostic Inventory-Revised) criteria. The definition of excessive or poor GWG varied across the studies; three studies used Institute of Medicine (IOM) guidelines to identify abnormal GWG. Chinese GWG guideline, GWG $\geq 18 \mathrm{~kg}$ as excess and $<7 \mathrm{~kg}$ as poor GWG, weight gained $<0.5 \mathrm{~kg} /$ week as poor GWG, and continuous model were other utilized methods to define abnormal GWG.

\section{Quality of articles}

All included studies were rated as good quality (Tables 3 and 4, Supplementary). The quality scores of all six cohort studies were 9, where 9 represents the lowest 


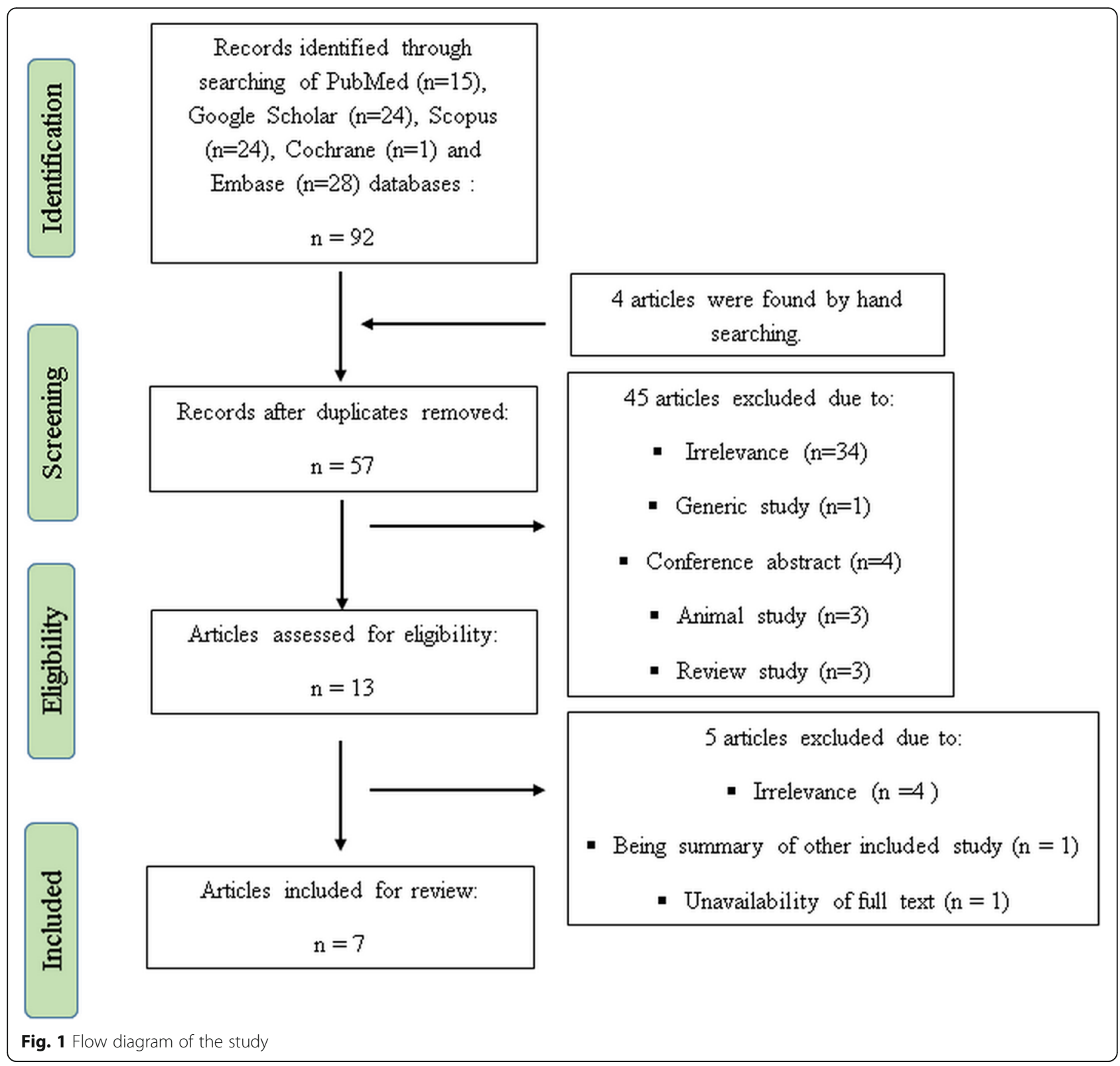

degree of bias (Table 3, Supplementary). The quality scores of two case-control studies ranged from 8 to 9 (Table 4, Supplementary).

\section{Maternal excessive GWG and risk of ASD in offspring}

As shown in Table 2, seven studies investigated the association of maternal high GWG with risk of ASD in offspring. All seven studies indicated that high GWG was significantly associated with increased risk of ASD. Dodds et al. [25], in a retrospective longitudinal cohort study over 129,733 births, diagnosed 924 children with ASD after 1 to 17 years follow up from birth, and found that GWG $\geq 18 \mathrm{~kg}$ was significantly correlated with an increased risk of ASD. Gardner et al. [26], in a cohort study with 333,057 children $\geq 4$ years, of whom 6420 were identified with ASD, reported that excessive GWG independently correlated with risk of ASD. In a casecontrol study, Shen et al. [28] found that greater GWG was associated with risk of ASD in the whole sample, also enhanced the risk of ASD in overweight/obese mothers. Windham et al. [29], also in a case-control study (ASD: $n=540$, control: $n=776$, aged 2 to 5 years), reported that excessive GWG was associated with risk of ASD, and, further, each 5-pound increase in GWG was correlated with $6 \%$ increased odds of ASD. Similar findings were also reported by two other studies (Table 2) [23, 30]. Bilder et al. [23] in a population-based cohort study (ASD: $n=128$, control: $n=10,920$ ) and in a 
Table 2 Characteristics and extracted data of the included studies

\begin{tabular}{|c|c|c|c|c|c|c|c|}
\hline $\begin{array}{l}\text { Author/ } \\
\text { year }\end{array}$ & Country & $\begin{array}{l}\text { Type of } \\
\text { study }\end{array}$ & $\begin{array}{l}\text { Number of } \\
\text { children/Type } \\
\text { of birth }\end{array}$ & $\begin{array}{l}\text { Age of } \\
\text { children } \\
\text { (year) }\end{array}$ & Covariates adjusted & $\begin{array}{l}\text { GWG } \\
\text { definition }\end{array}$ & $\begin{array}{l}\text { ASD } \\
\text { definition }\end{array}$ \\
\hline \multirow{2}{*}{$\begin{array}{l}\text { Bilder } \\
\text { et al./2013 } \\
\text { [23] }\end{array}$} & \multirow[t]{2}{*}{ Utah } & \multirow{2}{*}{$\begin{array}{l}\text { ADDM } \\
\text { Network } \\
\text { cohort } \\
\text { (Population- } \\
\text { based) }\end{array}$} & ASD, $n=128$ & 8 & \multirow{2}{*}{$\begin{array}{l}\text { Intellectual disability, } \\
\text { maternal and paternal age } \\
\text { and education, parity, pre- } \\
\text { pregnancy BMI, gesta- } \\
\text { tional age, gender, birth } \\
\text { year }\end{array}$} & \multirow{2}{*}{$\begin{array}{l}\text { Continuous } \\
\text { (based on a } \\
5-1 \mathrm{~b} \\
\text { increase) }\end{array}$} & \multirow[t]{2}{*}{ DSM-IV-TR } \\
\hline & & & $\begin{array}{l}\text { Control, } n=10, \\
920 / \text { Singleton } \\
\text { births }\end{array}$ & & & & \\
\hline \multirow{2}{*}{$\begin{array}{l}\text { Bilder } \\
\text { et al./2013 } \\
{[23]}\end{array}$} & \multirow[t]{2}{*}{ Utah } & \multirow{2}{*}{$\begin{array}{l}\text { Genetics } \\
\text { Study cohort } \\
\text { (research- } \\
\text { based) }\end{array}$} & ASD, $n=288$ & 8 & \multirow{2}{*}{$\begin{array}{l}\text { Intellectual disability, } \\
\text { maternal and paternal age } \\
\text { and education, parity, pre- } \\
\text { pregnancy BMI, gesta- } \\
\text { tional age, gender, birth } \\
\text { year }\end{array}$} & \multirow{2}{*}{$\begin{array}{l}\text { Continuous } \\
\text { (based on a } \\
5-1 b \\
\text { increase) }\end{array}$} & \multirow{2}{*}{$\begin{array}{l}\text { ADI-R and } \\
\text { ADOS-G }\end{array}$} \\
\hline & & & $\begin{array}{l}\text { Unaffected } \\
\text { siblings, } n= \\
\text { 493/Singleton } \\
\text { births }\end{array}$ & & & & \\
\hline
\end{tabular}

\begin{tabular}{|c|c|c|c|c|c|c|}
\hline $\begin{array}{l}\text { Burstyn } \\
\text { et al./2010 } \\
\text { [24] }\end{array}$ & Canada & Cohort & $\begin{array}{l}218,890 / \\
\text { Singleton births }\end{array}$ & $4-10$ & $\begin{array}{l}\text { Maternal age, weight, pre- } \\
\text { pregnancy and gestational } \\
\text { diabetes, bleeding, smok- } \\
\text { ing, parity and socio- } \\
\text { economic status, child's } \\
\text { birth year, gestational age, } \\
\text { gender }\end{array}$ & $\begin{array}{l}\text { Poor GWG: } \\
<0.5 \mathrm{~kg} / \\
\text { week (26- } \\
36 \text { weeks) }\end{array}$ \\
\hline
\end{tabular}

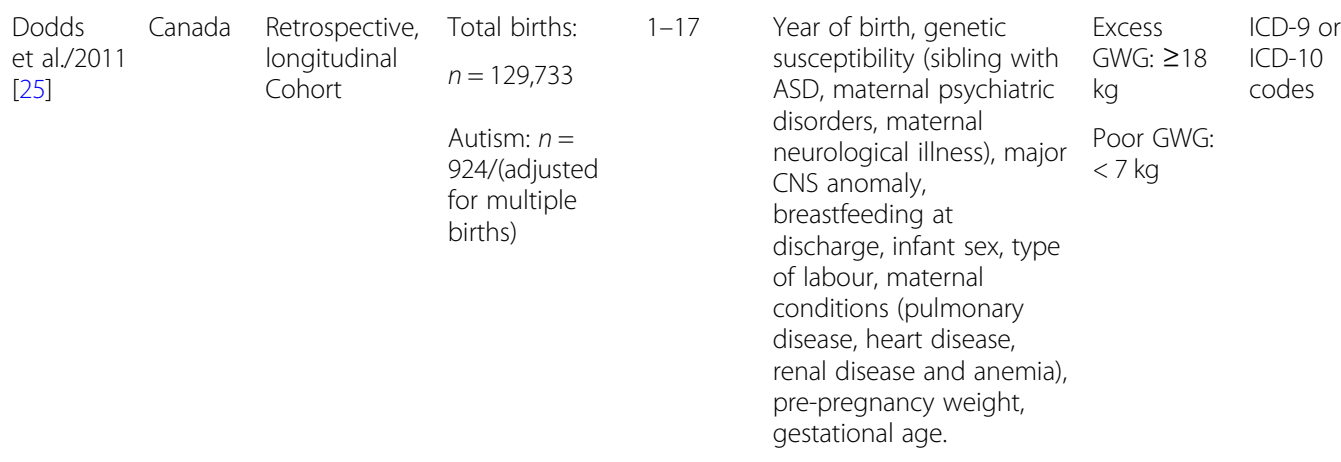

Findings OR $(95 \% \mathrm{Cl})$

Each 5 pounds of weight gained was significantly associated with ASD risk [1.10 (1.03-1.17)].

A 2 SD increase in GWG was associated with risk of ASD (25.00 lb).

Pre-pregnancy BMI was not associated with ASD.

Each 5 pounds of weight gained was significantly associated with ASD risk [1.17 (1.01-1.35)].

A 2 SD increase in GWG was associated with risk of ASD (24.74 lb).

Pre-pregnancy BMI was not associated with ASD.

Poor weight gain (26-36 weeks, < $0.5 \mathrm{~kg} /$ week) was not associated with increased risk of ASD [0.95 (0.57-1.59)].

Low maternal prepregnancy weight $(<45$ $\mathrm{kg}$ ) was associated with increased risk of ASD [RR: $2.15(1.20-3.85)]$

Maternal weight $>91 \mathrm{~kg}$ was not associated with increased risk of ASD [1.18 (0.96-1.44)].

GWG $\geq 18 \mathrm{~kg}$ in total sample [RR: 1.19 (1.021.39)] and in mothers of children with low genetic susceptibility [1.21 (1.031.43)] was associated with increased risk of autism.

Inadequate GWG $(<7 \mathrm{~kg})$ was not associated with the risk of autism.

Pre-pregnancy weight $\geq$ $90 \mathrm{~kg}$ in total sample [1.58 (1.26-1.98)] and in mothers of children with low genetic susceptibility [1.69 (1.34-2.14)] was associated with increased risk of autism.

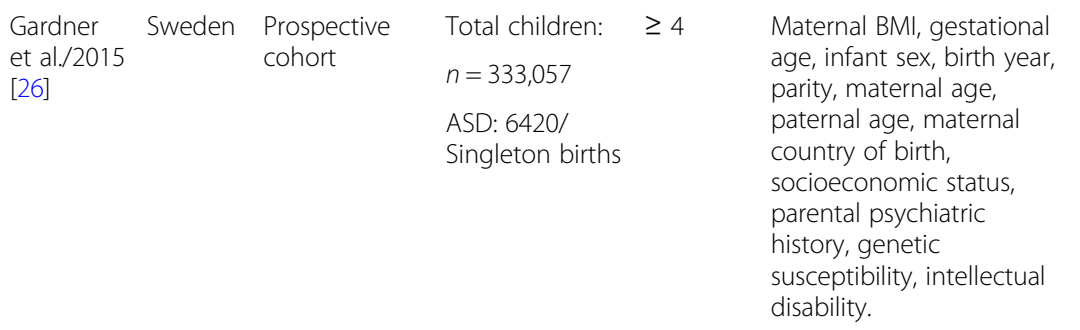

Based on ICD-9, ICD- Both insufficient [1.17 IOM 10, and (1.04-1.31)] and excessive guidelines DSM-IV GWG [1.12 (1.01-1.25)] codes were independently associated with ASD.

Every $2.3 \mathrm{~kg}(5 \mathrm{lb})$ increase in GWG was associated with increased risk of autism [1.03 (1.00-1.06)]. 
Table 2 Characteristics and extracted data of the included studies (Continued)

Author/ Country Type of Number of Age of Covariates adjusted year

\section{study}

children/Type of birth
GWG definition definition

Findings OR $(95 \% \mathrm{Cl})$

(year)
Shen
et al./2018

[28]

\section{China}

\section{Case-control}

(1)

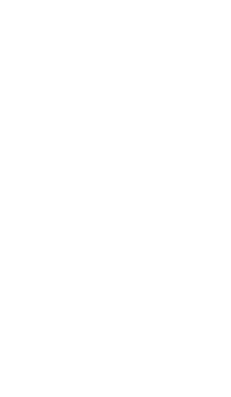

Windham USA

et al./2019

[29]

$\begin{array}{ll}\text { Case-control } & \text { ASD: } n=540 \quad 2-5 \\ \text { SEED } & \text { Developmental } \\ & \text { delays: } n=720 \\ & \text { Control: } \mathrm{n}= \\ & 776 / \text { Singleton } \\ & \text { births }\end{array}$

Control. $n=$ births

births
Matched sibling analyses showed elevated risk of ASD with excessive GWG [1.48 (0.93-2.38)].

Maternal overweight/ obesity was associated with increased risk of offspring ASD $[25 \leq$ $\mathrm{BMI}<30: 1.31,(1.21-1.41)$; $\mathrm{BMI} \geq 30$ : 1.94 (1.722.17)].
Child's gender and age, parental age and family income

Based on Chinese GWG guidelines

Pre-pregnancy BMI, maternal age, education, race/ethnicity, parity, smoking, intellectual disability, child sex
Based on

IOM

guidelines
DSM-IV-TR criteria

Excessive GWG was associated with autism risk in the entire sample [(1.327, 1.021-1.725)].

Excessive GWG increased the risk of autism in overweight/obese mothers [2.468 (1.1025.526)].

Inadequate GWG was not associated with the risk of autism.

Maternal pre-pregnancy BMI might not be independently associated with the risk of autism.

SCQ Maternal total GWG was score $\geq 11$, higher in the ASD group ADI-R, than other groups.

ADOS
Continuous model: 1.06 (1.02-1.10)

Exceeds IOM/ACOG recommendation: 1.29 (1.00-1.66)

Exceeding clinically recommended GWG was significantly higher (51\%) in ASD group than other groups.

Associations of ASD with higher GWG were stronger in quintiles 4 and 5.

Quintile $4(35-\leq 44$ pounds): 1.52 (1.05-2.22)

Quintile 5 ( $\geq 44$ pounds): $1.58(1.08-2.31)$

In the continuous model, each 5-pound increase of GWG was associated with6\% increased odds of ASD.

Insufficient GWG was not associated with risk of ASD.

Maternal pre-pregnancy 
Table 2 Characteristics and extracted data of the included studies (Continued)

\begin{tabular}{|c|c|c|c|c|c|c|c|c|}
\hline $\begin{array}{l}\text { Author/ } \\
\text { year }\end{array}$ & Country & $\begin{array}{l}\text { Type of } \\
\text { study }\end{array}$ & $\begin{array}{l}\text { Number of } \\
\text { children/Type } \\
\text { of birth }\end{array}$ & $\begin{array}{l}\text { Age of } \\
\text { children } \\
\text { (year) }\end{array}$ & Covariates adjusted & $\begin{array}{l}\text { GWG } \\
\text { definition }\end{array}$ & $\begin{array}{l}\text { ASD } \\
\text { definition }\end{array}$ & Findings OR (95\% CI) \\
\hline & & & & & & & & $\begin{array}{l}\text { BMI was not associated } \\
\text { with ASD. }\end{array}$ \\
\hline \multirow{2}{*}{$\begin{array}{l}\text { Xiang } \\
\text { et al./2015 } \\
{[30]}\end{array}$} & \multirow[t]{2}{*}{ USA } & \multirow{2}{*}{$\begin{array}{l}\text { Retrospective } \\
\text { longitudinal } \\
\text { cohort }\end{array}$} & $\begin{array}{l}322,323 \\
\text { children }\end{array}$ & \multirow{2}{*}{$\begin{array}{l}\text { A } \\
\text { median } \\
\text { of } 5.5 \\
\text { years } \\
\text { after } \\
\text { birth }\end{array}$} & \multirow{2}{*}{$\begin{array}{l}\text { Birth year, maternal age, } \\
\text { parity, gestational age, } \\
\text { education, maternal race/ } \\
\text { ethnicity, household } \\
\text { income, history of } \\
\text { comorbidity ( } \geq 1 \text { diagnosis } \\
\text { of heart, lung, kidney, or } \\
\text { liver disease; cancer), child } \\
\text { sex }\end{array}$} & \multirow[t]{2}{*}{$\begin{array}{l}\text { Continuous } \\
\text { (per } 4 \mathrm{~kg} \text { ) }\end{array}$} & \multirow{2}{*}{$\begin{array}{l}\text { ICD-9 } \\
\text { codes } \\
\text { 299.x or } \\
\text { equivalent } \\
\text { KPSC } \\
\text { codes }\end{array}$} & \multirow{2}{*}{$\begin{array}{l}\text { GWG (per } 4 \mathrm{~kg} \text { ) [HR: } 1.67 \\
(1.10-2.53)] \text { and maternal } \\
\text { pre-pregnancy BMI were } \\
\text { modestly and positively } \\
\text { associated with ASD risk. }\end{array}$} \\
\hline & & & $\begin{array}{l}\text { ASD: } n=3388 / \\
\text { Singleton births }\end{array}$ & & & & & \\
\hline
\end{tabular}

ADDM Autism and Developmental Disabilities Monitoring (ADDM); $A S D$ autism spectrum disorders; $B M I$ body mass index; $C l$ confidence interval; IOM Institute of Medicine; GWG gestational weight gain; HR Hazard Ratio; OR Odds Ratio; SEED the Study to Explore Early Development; RR Relative Risk; ICD International Statistical Classification of Diseases and Related Health Problems, 9th revision; DSM-IV-TR Diagnostic and Statistical Manual of Mental Disorders, fourth edition, text revision; ADOS-G Autism Diagnostic Observation Schedule-Generic; ADI-RAutism Diagnostic Inventory-Revised

genetic research-based study (ASD: $n=288$, unaffected siblings: $n=493$ ) on singleton births found that each 5 pounds of weight gained was significantly associated with increased risk of ASD. Xiang et al. [30] in a retrospective longitudinal cohort study on 322,323 singleton births (ASD: $n=3388$ ) reported that each $4 \mathrm{~kg}$ increase in GWG was positively associated with increased risk of ASD.

\section{Maternal insufficient GWG and risk of ASD in offspring}

As shown in Table 2, five studies investigated the association of inadequate GWG with risk of ASD in offspring. Four indicated that insufficient GWG was not associated with increased risk of ASD [24, 25, 28, 29]. Burstyn et al. [24], in a cohort study over 218,890 births, after 4-10 years follow up, reported that poor weight gain (26-36 weeks, $<0.5 \mathrm{~kg} /$ week) was not associated with increased risk of ASD. Dodds et al. [25], in a cohort study (total children: $n=129,733$; ASD: $n=924$; ages $1-17$ years) found that inadequate GWG $(<7 \mathrm{~kg})$ was not associated with increased risk of ASD. Shen et al. [28], in a casecontrol study (control: $n=2236$; ASD: $n=705$; ages 2-9 years) found that inadequate GWG (based on a Chinese recommendation) was not associated with increased risk of ASD. Windham et al. [29], in a case-control study (control: $n=776$; ASD: $n=540$; ages $2-5$ years) reported that insufficient GWG (based on IOM recommendation) was not associated with increased risk of ASD.

However, Gardner et al. [26], in a cohort study (total children: 333,057; ASD: 6420; ages $\geq 4$ years) reported that insufficient GWG (based on IOM recommendation) was independently associated with increased risk of ASD.

The role of child's genetic susceptibility and intellectual disability in the GWG-ASD relationship

Two of the included studies considered the confounding effect of the child's genetic susceptibility on the GWG-ASD relationship. One study reported that the significant relationship between GWG and ASD was independent of genetic susceptibility [25], while the other reported that the association may be influenced by the confounder factor [26].

Three reviewed studies addressed the role of child's intellectual disability in the GWG-ASD association [23, 26, 29]. All showed that excessive GWG increased the odds of ASD in ASD children with or without intellectual disability.

\section{The role of maternal pre-pregnancy BMI in GWG-ASD relationship}

Of the included studies, seven studies examined the association of maternal pre-pregnancy BMI $(n=5)$ or weight $(n=2)$ with risk of ASD in offspring (Table 2$)$. Five studies found that maternal pre-pregnancy BMI and weight $\geq 90 \mathrm{~kg}$ were not associated with increased risk of ASD in offspring [23 (population-based study and research-based study),24,28,29]. Bilder et al. [23] reported that maternal pre-pregnancy continuous BMI was not associated with ASD risk and concluded that GWG-ASD association was independent of prepregnancy BMI. Burstyn et al. [24] found that maternal pre-pregnancy weight $\geq 90 \mathrm{~kg}$ was not associated with increased risk of ASD in offspring. Shen et al. [28] showed that maternal pre-pregnancy low $(<18.5 \mathrm{~kg} / \mathrm{m} 2)$ and high $(>24 \mathrm{~kg} / \mathrm{m} 2)$ BMI were not significantly associated with risk of ASD. The author concluded that the maternal pre-pregnancy BMI might not be independently associated with ASD risk. Windham et al. [29] reported that maternal pre-pregnancy BMI (in all categories; < $18.5,25.0-29.9$ and $\geq 30 \mathrm{~kg} / \mathrm{m} 2$ ) was not associated with risk of ASD.

However, two studies reported contrary findings [25, 30]. Dodds et al. [25] showed that maternal prepregnancy high weight $(\geq 90 \mathrm{~kg}$ ) was associated with increased risk of ASD. Xiang et al. [30] found that maternal pre-pregnancy continuous BMI and BMI $\geq 30$ were positively associated with ASD risk. 
Nevertheless, in all studies that assessed the GWGASD relationship, the effect of maternal pre-pregnancy BMI or weight were considered and the observed link between GWG and ASD was independent.

\section{Discussion}

The findings of the present review showed that excessive maternal GWG is associated with higher risk of ASD in offspring. In this regard, it is important to pay attention to the following three pivotal points.

\section{Child's genetic susceptibility connection to the} association between maternal GWG and offspring ASD

In this respect, only two studies considered this point with two contrasting findings. Dodds et al. [25] reported that a significant relationship between GWG and ASD was independent of the child's genetic susceptibility, since the association remained significant when the analyses were restricted to children with high genetic susceptibility (having an autistic sibling or a mother with a psychiatric or neurologic disease). The result suggests that the observed association is unlikely to be attributable to familial confounding. Gardner et al., in a large study in Sweden [26], performed matched sibling analyses to compare affected children with their unaffected pairs to assess whether observed correlations between maternal GWG and offspring ASD might be the consequence of confounding by shared familial factors. The analysis showed that the association did not remain significant and this may indicate that the result could be influenced by residual confounding, although the authors did not reach this conclusion and suggested an elevated risk of ASD with excessive GWG in matched sibling analyses. Taken together, child's genetic susceptibility connection to the GWG-ASD association remains debatable and this area requires further investigation.

\section{Child's intellectual disability connection to the association between maternal GWG and offspring ASD}

Three of the included studies considered the role of child's intellectual disability in the association between maternal excessive GWG and offspring ASD. Bilder et al. [23] found that a significant GWG-ASD relationship was independent of the existence of comorbid intellectual disability among individuals with ASD, because the significant association persisted when analyses were limited to ASD children with a normal IQ. Windham et al. [29] found that elevated GWG similarly increased the odds of ASD in ASD children with or without intellectual disability. Similarly, Gardner et al. [26] showed that increased GWG similarly affected the odds of ASD in ASD children with or without intellectual disability across the entire studied population, while the odds of ASD in children without intellectual disability significantly increased in mothers with normal baseline BMI. Taken all together, it appears that the association between maternal excessive GWG and offspring ASD is independent of child's intellectual disability.

\section{Maternal BMI-GWG interaction and risk of offspring ASD}

Although most studies considered the confounding role of maternal pre-pregnancy BMI in GWG-ASD relationship and indicated that excessive GWG might increase the risk of ASD independent of BMI, however, several studies suggested an interaction between maternal BMI and GWG leading to increased risk of ASD in offspring. Shen et al. [28] found that the risk of ASD significantly rose in mothers with high pre-pregnancy BMI along with greater GWG. The authors concluded that the interaction between maternal BMI and GWG was significantly related to offspring ASD risk. Windham et al. [29] reported that the GWG-ASD association did not change by BMI in a continuous model. However, mothers with high BMI were more likely to have excessive weight gain $(\sim 55 \%)$ than mothers of normal weight $(\sim 35 \%)$ and the relation of ASD to greater GWG was more obvious, although non-significant, in overweight/ obese mothers. Nevertheless, Gardner et al. [26] found when the analysis of GWG-ASD association was limited to mothers with a normal pre-pregnancy BMI for differentiating potential impacts of GWG from baseline BMI, the risk pattern did not change compared to the entire sample. The authors suggested that excessive GWG was independent of BMI correlated with ASD. Collectively, it is speculated that the association of GWG-ASD independent of maternal $\mathrm{BMI}$ is prevailing; however, further investigations are warranted.

Most of the studies used the WHO categorization of BMI [32]; however, two studies used continuous BMI for analysis and two used pre-pregnancy weight instead of BMI, which limits comparability of the results with respect to the BMI-GWG-ASD association.

\section{Fetus gender connection to the GWG-ASD association}

ASD is a sex-specific neurological condition which affects more males than females. This may indicate that underlying mechanisms of sex differentiation may contribute to the neurobiology of ASD. Sex-specific differences in the occurrence of ASD may be attributable to sex-hormone specific effects. High perinatal testosterone levels have been suggested as a potential risk factor for neurodevelopmental disorders, including ASD [33-37]. In this regard, male fetuses would be more affected since testosterone concentration in the amniotic fluid of male fetuses is significantly higher than those of female fetuses at all stages of gestation [38]. The results of this review showed that high GWG may be a risk factor for ASD. According to some evidence, high GWG is 
accompanied by high testosterone levels [39]. This may indicate that child neurodevelopment may be associated with GWG in a sex-specific manner. It is suggested that fetal testosterone level to be taken into account in the analyzing of the relationship between GWG and risk of ASD.

\section{Mechanisms for the relationship between maternal excessive GWG and offspring ASD risk}

None of the articles reviewed mechanistically studied the role of GWG on ASD risk and the underlying mechanisms connecting maternal excessive GWG to offspring ASD remain unclear. However, the dysregulation of steroid hormones, leptin, and pro-inflammatory cytokines during gestation have been projected as possible mechanisms involved in psychopathology. Endogenous steroid hormones (for example, testosterone, estrogen, progesterone, or cortisol) released by mother, placenta, and fetal gonads and adrenal glands generate a fetal steroid environment [40]. These steroid hormones, as environmental factors, may influence fetal gene transcription and expression through DNA binding during susceptible stages of embryonic development [40]. Any impairment in the fetal steroid hormone environment can lead to dysfunction in the body or even death. Inappropriate levels of fetal steroid hormones such as increased fetal testosterone levels have been reported to be associated with autistic traits [33-35]. As well, a positive relationship has been reported between increased levels of amniotic steroid hormones and ASD [41]. Lof et al. [42], in a longitudinal study of Swedish women, found that plasma levels of progesterone during pregnancy were positively associated with GWG.

Disturbance of leptin is another suggested mechanism contributing to psychopathology. Leptin has a vital role in fetal growth and development during pregnancy [43]. Any dysregulation in fetal leptin levels leads to mental health impairments and neurodevelopmental disorders, including ASD [44]. High plasma leptin in early childhood has been proposed as a potential biomarker for ASD [45] and increased circulating leptin is consistently observed in individuals with ASD [44, 46, 47]. According to previous investigations, fetal leptin levels are affected by maternal leptin levels [48, 49]. Walsh et al. [49] demonstrated an association between maternal and fetal leptin levels at each time point of pregnancy period. Elevated levels of leptin have also been reported in the placental vascular endothelial cells which are associated with maternal obesity [50]. Variation in the interchange of leptin among mother, placenta, and fetus may influence the development of the fetus and increase the risk of disease in later life [51]. Higher maternal leptin levels have also been shown to be associated with greater GWG [52]. The results of two birth cohort studies found that excessive GWG correlated with greater leptin levels in either cord blood or post-delivery maternal serum [53]. Patro-Małysza et al. [54] also reported greater umbilical cord leptin levels in neonates born to mothers with excessive GWG. Further, Vargas-Aguirre at al [55]. found that umbilical cord blood leptin levels were higher in neonates born to mothers with high GWG. Collectively, it is thought that excessive GWG may likely associate with in-utero leptin disturbance, which in turn may lead to increased risk of ASD. However, further studies are needed to support the association of fetal leptin levels and risk of ASD.

Leptin is able to cross the blood-brain barrier and enter the brain. As shown in Fig. 2, the brain leptin-glutamate or leptin-serotonin interactions have been proposed as possible mechanisms involved in the development of neurodevelopmental disorders, including ASD. Serotonin and glutamate are well-known neurotransmitters that have critical roles in neural activities and social behaviors. Clinically, abnormal levels of these neurotransmitters are linked with many neurodevelopmental disorders, including ASD [56, 57]. Serotonin regulates neural development and alterations in its concentration during development can have life-long effects. Exposure to abnormal levels of serotonin during the prenatal period may contribute to behavioral impairments in adulthood [58]. Excessive levels of glutamate have also been reported to have neurotoxic properties [59]. Calapai et al. [60] demonstrated that leptin injections caused a dose-dependent increase of serotonin in mice. Yadav et al. [61] showed that leptin decreased serotonin synthesis and prevented neuronal activity of serotonergic neurons in the ventromedial hypothalamus. Haque and Haleem [62] indicated that serum leptin was inversely associated with circulating serotonin in working men. Fuente-Martín et al. [63] reported that leptin regulated astrocyte-specific glutamate. Further, Yu and Cai [64] showed that excess central leptin increased glutamatergic pathway activation.

Interaction of steroid hormones with the neurotransmitters is another possible pathway for the development of neurodevelopmental disorders (Fig. 2). Zlotnik et al. [65], in a study on men and women, showed that blood glutamate levels were negatively associated with plasma levels of estrogen and progesterone. Raz et al. [66] found that serotonin was regulated by sex steroid hormones and could influence mood. Ladisich [67] found that progesterone injections dose-dependently increased serotonin turnover. According to the evidence, steroid hormones are linked to the regulation of leptin and the leptin receptor [68-70]. Thus, steroid hormones might indirectly contribute to the pathogenesis of ASD through the leptin interface. However, more research is required to confirm the interaction of leptin or steroid hormones with the neurotransmitters involved in occurrence of ASD, in the prenatal period. The role of neuroinflammation in the 


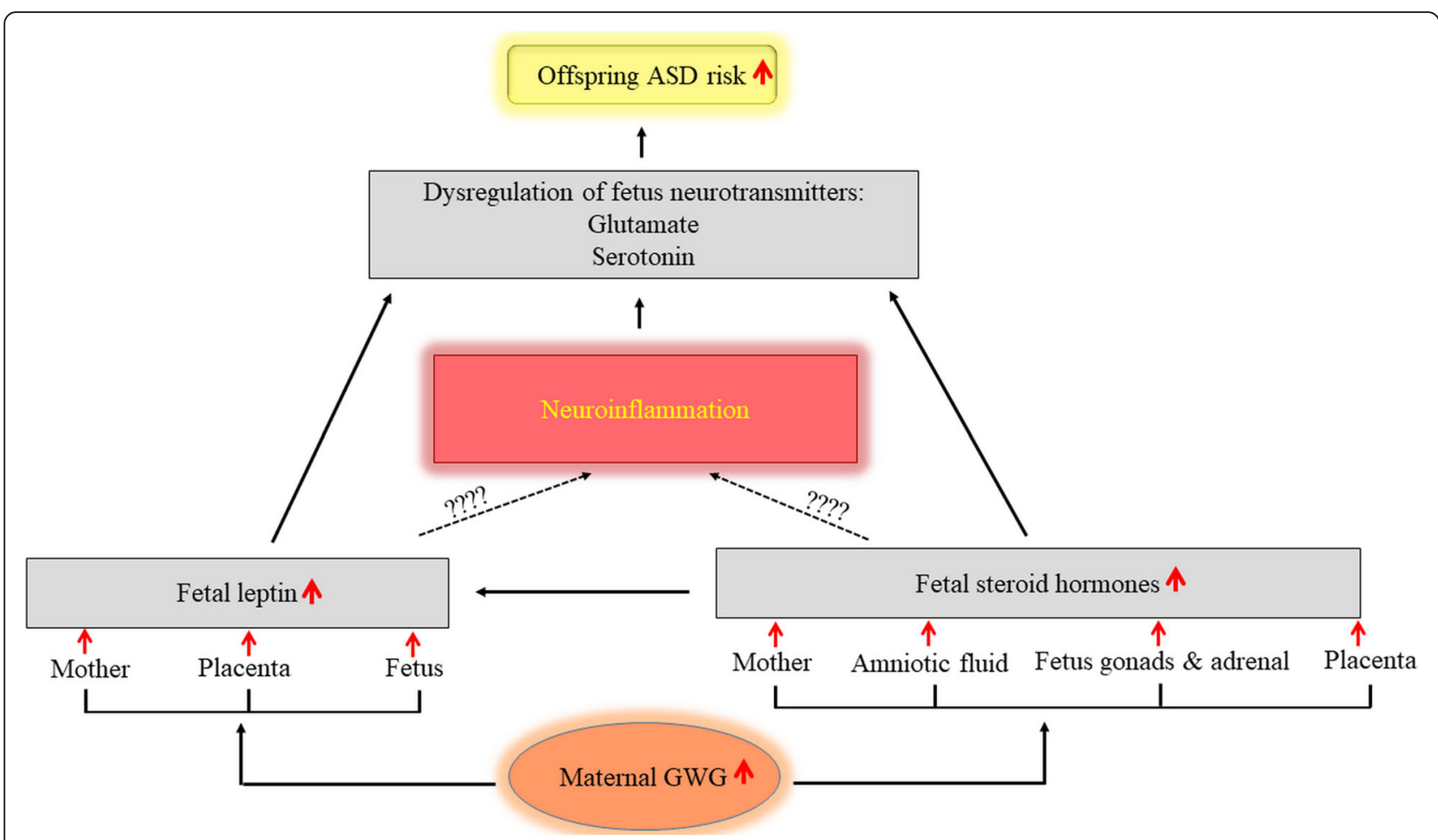

Fig. 2 A possible mechanistic model of GWG and ASD relationship. ASD, autism spectrum disorders; GWG, gestational weight gain

projected pathways should also be a focus for future study.

\section{Conclusion}

The findings suggest that increased risk of offspring ASD is associated with maternal excessive GWG and is not likely with insufficient GWG. The inclusion of several cohort studies with very large sample sizes ( $>300$, 000 participants), in particular a prospective cohort study, in the current review may possibly enhance the power of these findings. It appears that the association between maternal excessive GWG and offspring ASD is independent of maternal BMI and child intellectual disability. Further investigation is needed to clarify the impact of child's genetic susceptibility on the association between maternal GWG and offspring ASD. More research is required with regards to interaction between GWG and biochemicals involved in the etiology or pathophysiology of ASD in the prenatal period.

\section{Application of the findings}

This study highlights that pregnancy excessive weight gain, which exhibits the metabolic and nutritional condition of the mother throughout pregnancy, may have long-term neurodevelopmental effects on children and could be employed as a serious predictive biomarker of ASD. Focusing attention on helping women adhere to
GWG guidelines is imperative to achieving a healthy weight gain during pregnancy.

\section{Strengths of the study}

Using large sample sizes and consideration of the role of potential confounding factors in the GWG-ASD association in the included studies were strengths of the study.

\section{Limitations of the study}

Various criteria were used to identify ASD and GWG across the studies, which may influence the comparability of the results. None of the studies investigated the role of biochemical markers such as leptin, steroid hormones, neurotransmitters, or neuropeptides involved in the pathogenesis of ASD in the prenatal period to determine underlying mechanisms connecting maternal excessive GWG with offspring ASD.

\section{Supplementary information}

Supplementary information accompanies this paper at https://doi.org/10. 1186/s12884-020-03324-w.

Additional file $\mathbf{1}$ Table S3. Newcastle-Ottawa scale for assessment of quality of six included cohort studies assessing the relationship of gestational weight gain and risk of autism spectrum disorder (each asterisk represents if individual criterion within the subsection was fulfilled)

Additional file $\mathbf{2}$ Table S4. Newcastle-Ottawa scale for assessment of quality of three selected case-control studies assessing the relationship between gestational weight gain and risk of autism spectrum disorders 
(each asterisk represents if individual criterion within the subsection was fulfilled)

\section{Abbreviations}

ASD: Autism spectrum disorders; BMI: Body mass index; IOM: Institute of Medicine; GWG: Gestational weight gain

\section{Acknowledgements}

Not applicable.

\section{Authors' contributions}

SK and MD were involved in the searching and selection of the articles, data extraction and participated in manuscript writing. Both of the authors (SK and $\mathrm{MD}$ ) read and approved the final manuscript.

\section{Funding}

Tabriz University of Medical Sciences supported this study financially.

\section{Availability of data and materials}

All data extracted from the studies are included in this published article.

\section{Ethics approval and consent to participate}

The protocol of the study was registered and approved in the Research Vice Chancellor of Tabriz University of Medical Sciences (IR.TBZMED.REC.1398.456(.

\section{Consent for publication}

Not applicable.

\section{Competing interests}

The authors declare that they have no competing interests.

Received: 16 March 2020 Accepted: 9 October 2020

Published online: 22 October 2020

\section{References}

1. CDC; Autism Statistics and Facts. Autism Speaks; 2020 https://www. autismspeaks.org/autism-statistics.

2. Lord C, Elsabbagh M, Baird G, Veenstra-Vanderweele J. Autism spectrum disorder. Lancet. 2018;392:508-20. https://doi.org/10.1016/S01406736(18)31129-2.

3. Freitag CM, Staal W, Klauck SM, Duketis E, Waltes R. Genetics of autistic disorders: review and clinical implications. Eur Child Adolesc Psychiatry. 2010;19:169-78. https://doi.org/10.1007/s00787-009-0076-x.

4. Gardener H, Spiegelman D, Buka SL. Perinatal and neonatal risk factors for autism: a comprehensive meta-analysis. Pediatrics. 2011;128:344-55. https:// doi.org/10.1542/peds.2010-1036.

5. Lefebvre A, Beggiato A, Bourgeron T, Toro R. Neuroanatomical diversity of corpus callosum and brain volume in autism: meta-analysis, analysis of the autism brain imaging data exchange project, and simulation. Biol Psychiatry. 2015;78:126-34. https://doi.org/10.1016/j.biopsych.2015.02.010.

6. Ecker $C$. The neuroanatomy of autism spectrum disorder: an overview of structural neuroimaging findings and their translatability to the clinical setting. Autism. 2017;21:18-28. https://doi.org/10.1177/1362361315627136.

7. Donovan AP, Basson MA. The neuroanatomy of autism - a developmental perspective. J Anat. 2017;230:4-15. https://doi.org/10.1111/joa.12542.

8. Karimi P, Kamali E, Mousavi SM, Karahmadi M. Environmental factors influencing the risk of autism. J Res Med Sci. 2017;22:27. https://doi.org/10. 4103/1735-1995.200272 eCollection 2017.

9. Bonnet-Brilhault F, Rajerison TA, Paillet $C$, et al. Autism is a prenatal disorder: evidence from late gestation brain overgrowth. Autism Res. 2018:11:163542. https://doi.org/10.1002/aur.2036

10. Wan H, Zhang C, Li H, Luan S, Liu C. Association of maternal diabetes with autism spectrum disorders in offspring: A systemic review and metaanalysis. Medicine (Baltimore). 2018;97:e9438. https://doi.org/10.1097/MD 0000000000009438.

11. Gardener H, Spiegelman D, Buka SL. Prenatal risk factors for autism: comprehensive meta-analysis. Br J Psychiatry. 2009;195:7-14. https://doi.org/ 10.1192/bjp.bp.108.051672.
12. Wu S, Wu F, Ding Y, Hou J, Bi J, Zhang Z. Advanced parental age and autism risk in children: a systematic review and meta-analysis. Acta Psychiatr Scand. 2017;135:29-41. https://doi.org/10.1111/acps.12666.

13. Morales DR, Slattery J, Evans S, Kurz X. Antidepressant use during pregnancy and risk of autism spectrum disorder and attention deficit hyperactivity disorder: systematic review of observational studies and methodological considerations. BMC Med. 2018;16:6. https://doi.org/10.1186/s12916-0170993-3.

14. Christensen J, Grønborg TK, Sørensen MJ, et al. Prenatal valproate exposure and risk of autism spectrum disorders and childhood autism. JAMA. 2013; 309:1696-703. https://doi.org/10.1001/jama.2013.2270.

15. Miller KM, Xing G, Walker CK. Meconium exposure and autism risk. J Perinatol. 2017;37:203-7. https://doi.org/10.1038/jp.2016.200.

16. Cunningham SD, Mokshagundam S, Chai H, et al. Postpartum depressive symptoms: gestational weight gain as a risk factor for adolescents who are overweight or obese. J Midwifery Womens Health. 2018;63:178-84. https:// doi.org/10.1111/jmwh.12686.

17. Dayan F, Javadifar N, Tadayon M, Malehi AS, Komeili SH. The relationship between gestational weight gain and postpartum depression in Normal and overweight pregnant women. J Pregnancy. 2018;2018:9315320. https:// doi.org/10.1155/2018/9315320 eCollection 2018

18. Pugh SJ, Richardson GA, Hutcheon JA, et al. Maternal obesity and excessive gestational weight gain are associated with components of child cognition. J Nutr. 2015;145:2562-9. https://doi.org/10.3945/jn.115.215525.

19. Keim SA, Pruitt NT. Gestational weight gain and child cognitive development. Int J Epidemiol. 2012;41:414-22. https://doi.org/10.1093/ije/ dyr229.

20. Goldstein RF, Abell SK, Ranasinha S, et al. Association of gestational weight gain with maternal and infant outcomes: a systematic review and metaanalysis. JAMA. 2017:317:2207-25. https://doi.org/10.1001/jama.2017.3635.

21. Fuemmeler BF, Zucker $N$, Sheng $Y$, et al. Pre-Pregnancy weight and symptoms of attention deficit hyperactivity disorder and executive functioning behaviors in preschool children. Int J Environ Res Public Health. 2019:16:E667. https://doi.org/10.3390/ijerph16040667.

22. Diesel JC, Eckhardt CL, Day NL, Brooks MM, Arslanian SA, Bodnar LM. Gestational weight gain and the risk of offspring obesity at 10 and 16 years: a prospective cohort study in low-income women. BJOG. 2015;122:1395402. https://doi.org/10.1111/1471-0528.13448.

23. Bilder DA, Bakian AV, Viskochil J, et al. Maternal prenatal weight gain and autism spectrum disorders. Pediatrics. 2013;132:e1276-83. https://doi.org/10. 1542/peds.2013-1188.

24. Burstyn I, Sithole F, Zwaigenbaum L. Autism spectrum disorders, maternal characteristics and obstetric complications among singletons born in Alberta, Canada. Chronic Dis Can. 2010;30:125-34.

25. Dodds $L$, Fell DB, Shea S, Armson BA, Allen AC, Bryson S. The role of prenatal, obstetric and neonatal factors in the development of autism. J Autism Dev Disord. 2011;41:891-902. https://doi.org/10.1007/s10803-0101114-8.

26. Gardner RM, Lee BK, Magnusson C, et al. Maternal body mass index during early pregnancy, gestational weight gain, and risk of autism spectrum disorders: results from a Swedish total population and discordant sibling study. Int J Epidemiol. 2015;44:870-83. https://doi.org/10.1093/ije/dyv081.

27. Ling Z, Wang J, Li $X$, et al. Association between mothers' body mass index before pregnancy or weight gain during pregnancy and autism in children. Zhonghua Liu Xing Bing Xue Za Zhi. 2015;36:949-52 Article in Chinese.

28. Shen Y, Dong H, Lu X, et al. Associations among maternal pre-pregnancy body mass index, gestational weight gain and risk of autism in the Han Chinese population. BMC Psychiatry. 2018;18:11. https://doi.org/10.1186/ s12888-018-1593-2.

29. Windham GC, Anderson M, Lyall K, et al. Maternal pre-pregnancy body mass index and gestational weight gain in relation to autism spectrum disorder and other developmental disorders in offspring. Autism Res. 2019:12:316-27. https://doi.org/10.1002/aur.2057.

30. Xiang $A H$, Wang $X$, Martinez MP, et al. Association of maternal diabetes with autism in offspring. JAMA. 2015;313:1425-34. https://doi.org/10.1001/jama. 2015.2707.

31. Wells GA, Shea B, O'Connell D, Peterson J, Welch V, Losos M, Tugwell P. The Newcastle-Ottawa scale (NOS) for assessing the quality of nonrandomised studies in meta-analyses. Contact details: professor GA Wells, Department of Epidemiology and Commuunity Medicine, University of Ottawa, room 3227A, 451 Smyth road, Ottawa, Ontario K1J 8M5, Canada. 
32. WHO/Europe- Body mass index - BMl- Nutrition; https://www.euro.who.int/ en/health-topics/disease-prevention/nutrition/a-healthy-lifestyle/body-massindex-bmi.

33. Auyeung B, Taylor K, Hackett G, Baron-Cohen S. Foetal testosterone and autistic traits in 18 to 24-month-old children. Mol Autism. 2010;1:11. https:// doi.org/10.1186/2040-2392-1-11.

34. Auyeung B, Ahluwalia J, Thomson L, et al. Prenatal versus postnatal sex steroid hormone effects on autistic traits in children at 18 to 24 months of age. Mol Autism. 2012;3:17. https://doi.org/10.1186/2040-2392-3-17.

35. Auyeung B, Baron-Cohen S, Ashwin E, Knickmeyer R, Taylor K, Hackett G. Fetal testosterone and autistic traits. Br J Psychol. 2009;100:1-22. https://doi. org/10.1348/000712608X311731.

36. Geschwind N, Galaburda AM. Cerebral lateralization. Biological mechanisms, associations, and pathology: I. a hypothesis and a program for research. Arch Neurol. 1985;42:428-59. https://doi.org/10.1001/archneur.1985. 04060050026008.

37. Morris JA, Jordan CL, Breedlove SM. Sexual differentiation of the vertebrate nervous system. Nat Neurosci. 2004;7:1034-9. https://doi.org/10.1038/ nn1325.

38. Finegan JA, Bartleman B, Wong PY. A window for the study of prenatal sex hormone influences on postnatal development. J Genet Psychol. 1989;150: 101-12. https://doi.org/10.1080/00221325.1989.9914580.

39. Kallak TK, Hellgren C, Skalkidou A, et al. Maternal and female fetal testosterone levels are associated with maternal age and gestational weight gain. Eur J Endocrinol. 2017;177:379-88. https://doi.org/10.1530/EJE-17-0207.

40. Gore AC, Martien KM, Gagnidze K, Pfaff D. Implications of prenatal steroid perturbations for neurodevelopment, behavior, and autism. Endocr Rev. 2014;35:961-91. https://doi.org/10.1210/er.2013-1122

41. Baron-Cohen S, Auyeung B, Nørgaard-Pedersen B, et al. Elevated fetal steroidogenic activity in autism. Mol Psychiatry. 2015;20:369-76. https://doi. org/10.1038/mp.2014.48.

42. Lof M, Hilakivi-Clarke L, Sandin S, de Assis S, Yu W, Weiderpass E. Dietary fat intake and gestational weight gain in relation to estradiol and progesterone plasma levels during pregnancy: a longitudinal study in Swedish women. BMC Womens Health. 2009;9:10. https://doi.org/10.1186/1472-6874-9-10.

43. Grisaru-Granovsky S, Samueloff A, Elstein D. The role of leptin in fetal growth: a short review from conception to delivery. Eur J Obstet Gynecol Reprod Biol. 2008;136:146-50

44. Valleau JC, Sullivan EL. The impact of leptin on perinatal development and psychopathology. J Chem Neuroanat. 2014;61-62:221-32. https://doi.org/10. 1016/j.jchemneu.2014.05.001.

45. Raghavan R, Zuckerman B, Hong X, et al. Fetal and infancy growth pattern, cord and early childhood plasma leptin, and development of autism spectrum disorder in the Boston birth cohort. Autism Res. 2018;11:1416-31. https://doi.org/10.1002/aur.2011.

46. Ashwood P, Kwong C, Hansen R, et al. Brief report: plasma leptin levels are elevated in autism: association with early onset phenotype? J Autism Dev Disord. 2008;38:169-75.

47. Al-Zaid FS, Alhader AA, Al-Ayadhi LY. Altered ghrelin levels in boys with autism: a novel finding associated with hormonal dysregulation. Sci Rep. 2014:4:6478. https://doi.org/10.1038/srep06478.

48. Luo ZC, Nuyt AM, Delvin E, et al. Maternal and fetal leptin, adiponectin levels and associations with fetal insulin sensitivity. Obesity (Silver Spring). 2013;21:210-6. https://doi.org/10.1002/oby.20250.

49. Walsh JM, Byrne J, Mahony RM, Foley ME, McAuliffe FM. Leptin, fetal growth and insulin resistance in non-diabetic pregnancies. Early Hum Dev. 2014;90: 271-4. https://doi.org/10.1016/j.earlhumdev.2014.03.007.

50. Tsai PJ, Davis J, Bryant-Greenwood G. Systemic and placental leptin and its receptors in pregnancies associated with obesity. Reprod Sci. 2015;22:189_ 97. https://doi.org/10.1177/1933719114537718.

51. Briffa JF, McAinch AJ, Romano T, Wlodek ME, Hryciw DH. Leptin in pregnancy and development: a contributor to adulthood disease? Am J Physiol Endocrinol Metab. 2015;308:E335-50. https://doi.org/10.1152/ ajpendo.00312.2014

52. Lacroix M, Battista MC, Doyon M, et al. Higher maternal leptin levels at second trimester are associated with subsequent greater gestational weight gain. BMC Pregnancy Childbirth. 2016;16:62. https://doi.org/10.1186/s12884016-0842-y.

53. Logan CA, Bornemann R, Koenig W, et al. Gestational weight gain and fetalmaternal adiponectin, leptin, and CRP: results of two birth cohorts studies. Sci Rep. 2017;7:41847. https://doi.org/10.1038/srep41847.
54. Patro-Małysza J, Trojnar M, Skórzyńska-Dziduszko KE, et al. Leptin and ghrelin in excessive gestational weight gain-association between mothers and offspring. Int J Mol Sci. 2019;20(10):2398. https://doi.org/10.3390/ ijms20102398.

55. Vargas-Aguirre P, Tene CE, Toro-Equihua MD, Bayardo-Tortolero R, SánchezMeza K. Comparison of leptin levels in neonates born to mothers with high or low gestational weight gain. J Pediatr Endocrinol Metab. 2020;33(4):51723. https://doi.org/10.1515/jpem-2019-0356.

56. Rojas DC. The role of glutamate and its receptors in autism and the use of glutamate receptor antagonists in treatment. J Neural Transm (Vienna). 2014;121:891-905. https://doi.org/10.1007/s00702-014-1216-0.

57. Muller CL, Anacker AMJ, Veenstra-VanderWeele J. The serotonin system in autism spectrum disorder: from biomarker to animal models. Neuroscience. 2016;321:24-41. https://doi.org/10.1016/j.neuroscience.2015.11.010.

58. Shah R, Courtiol E, Castellanos FX, Teixeira CM. Abnormal serotonin levels during perinatal development lead to behavioral deficits in adulthood. Front Behav Neurosci. 2018;12:114. https://doi.org/10.3389/fnbeh.2018.00114 eCollection 2018.

59. Zheng Z, Zhu T, Qu Y, Mu D. Blood glutamate levels in autism spectrum disorder: a systematic review and meta-analysis. PLoS One. 2016;11: e0158688. https://doi.org/10.1371/journal.pone.0158688 eCollection 2016.

60. Calapai G, Corica F, Corsonello A, et al. Leptin increases serotonin turnover by inhibition of brain nitric oxide synthesis. J Clin Invest. 1999;104:975-82.

61. Yadav VK, Oury F, Suda N, et al. A serotonin-dependent mechanism explains the leptin regulation of bone mass, appetite, and energy expenditure. Cell. 2009;138:976-89. https://doi.org/10.1016/j.cell.2009.06.051.

62. Haque Z, Haleem DJ. The interaction of serum serotonin, cortisol and leptin in stress related obesity in working men at educational institutions of Karachi. Karachi University J Science. 2010;38:23-7.

63. Fuente-Martín E, García-Cáceres C, Granado M, et al. Leptin regulates glutamate and glucose transporters in hypothalamic astrocytes. J Clin Invest. 2012;122:3900-13. https://doi.org/10.1172/JCI64102.

64. Yu B, Cai D. Neural programmatic role of leptin, TNFa, melanocortin, and glutamate in blood pressure regulation vs obesity-related hypertension in male C57BL/6 mice. Endocrinology. 2017;158:1766-75. https://doi.org/10. 1210/en.2016-1872.

65. Zlotnik A, Gruenbaum BF, Mohar B, et al. The effects of estrogen and progesterone on blood glutamate levels: evidence from changes of blood glutamate levels during the menstrual cycle in women. Biol Reprod. 2011; 84:581-6. https://doi.org/10.1095/biolreprod.110.088120.

66. Raz L, Hunter LV, Dowling NM, et al. Differential effects of hormone therapy on serotonin, vascular function and mood in the KEEPS. Climacteric. 2016; 19:49-59. https://doi.org/10.3109/13697137.2015.1116504.

67. Ladisich W. Influence of progesterone on serotonin metabolism: a possible causal factor for mood changes. Psychoneuroendocrinology. 1977;2:257-66.

68. Tanaka M, Nakaya S, Kumai T, et al. Effects of estrogen on serum leptin levels and leptin mRNA expression in adipose tissue in rats. Horm Res. 2001; 56:98-104.

69. Fungfuang W, Terada M, Komatsu N, Moon C, Saito TR. Effects of estrogen on food intake, serum leptin levels and leptin mRNA expression in adipose tissue of female rats. Lab Anim Res. 2013;29:168-73. https://doi.org/10.5625/ lar.2013.29.3.168

70. Cella F, Giordano G, Cordera R. Serum leptin concentrations during the menstrual cycle in normal-weight women: effects of an oral triphasic estrogen-progestin medication. Eur J Endocrinol. 2000;142:174-8.

\section{Publisher's Note}

Springer Nature remains neutral with regard to jurisdictional claims in published maps and institutional affiliations. 